\title{
Estimation of Pore Volume Compressibility in Carbonate Reservoir Rocks based on a Classification
}

Seyed Amin Moosavi ( $\sim$ aminmoosavi@vru.ac.ir)

Vali-e-Asr University of Rafsanjan https://orcid.org/0000-0003-4196-0158

Hesam Aloki Bakhtiari

RIPI: Research Institute of Petroleum Industry

Javad Honarmand

RIPI: Research Institute of Petroleum Industry

\section{Research Article}

Keywords: Pore Volume Compressibility, Classification, Porosity, Permeability, Stress

Posted Date: April 22nd, 2021

DOI: https://doi.org/10.21203/rs.3.rs-429413/v1

License: () (i) This work is licensed under a Creative Commons Attribution 4.0 International License. Read Full License

Version of Record: A version of this preprint was published at Geotechnical and Geological Engineering on March 7th, 2022. See the published version at https://doi.org/10.1007/s10706-022-02089-7. 


\section{Abstract}

Taking a vast range of carbonate reservoir rock from Asmari and Bangestan formations in southern Iran basins, this study examined the petrographically classification, petrological and petrophysical characteristics, and their implications on the estimation of pore volume compressibility of the carbonate reservoirs. In the current study, a method is developed to classify the carbonate reservoir rocks based on the dominant factors which is involving in elastic property of pore volumes. In order to classifying, a number of 3702 thin sections were studied. Then, the pore volume compressibility of 200 core plugs corresponding to the range of classification parameters were obtained and quantified by a pre-proven equation. The results clearly show an acceptable narrow bandwidth between the upper and lower bound of estimations based on the studied classification. Furthermore, the estimation of pore compressibility-stress relationship was in a good agreement with the experimental observations. Also, the study shows that integrating the routine petrophysical properties are useful for estimation of stress related properties of pore volumes into carbonate reservoir rocks.

\section{Introduction}

Hydrocarbon production operations can cause reservoir compaction due to reduction in pore fluid pressure and subsequent changes in external effective stress (Geertsma, 1957). In order to study the reservoir compaction, it is necessary to the know compressibility characteristics of the reservoir rock. Pore volume compressibility (PVC) is one of the most kinds of compressibility of porous media (Teeuw, 1971). The PVC of reservoir rock is usually measured by change in pore volume at different levels of pore pressure in laboratory. In most of the cases, laboratory determination of PVC has encountered with some difficulty due to difficulty in accurate core sample acquisition, as well as time and cost consuming sample preparation procedure. In other situation, sometimes the lake of appropriate core sample from the reservoir is another shortage which may encounter to achieve an accurate value for PVC. So, most of the researchers have been proposed empirical relation to estimate PVC (Chuanliang et al., 2004; da Silva et al., 2015; Hall, 1953; Harari et al., 1995; Horne, 1997; Jalalh, 2006a, b; Newman, 1973). Hall (1953) proposed a simple inverse equation between PVC and porosity based on experimental measurements. In order to evaluate the accuracy of the PVC models previously published by Hall (1953), van der Knaap (1959), Horne (1997) and Jalalh (2006b), in an experimental study da Silva et al. (2015) have investigated the petrophysical properties of carbonate rocks from North America from three distinctive geologic backgrounds. They have represented better accuracy of the Jalalh (2006b) model with respect to the Hall (1953) as a function of porosity.

The main shortcoming of these equations was that the influence of rock lithology was not taken place, and for different lithologies with the same porosity, it proposed the same value for PVC. However, pore volume compressibility of reservoir rock is related not only to porosity but also to elastic properties of the constituents, which is affected by the microstructural petrological characteristics, as well. Macroscopic properties of porous rock are essentially closely related to its microstructural characteristics. Different researchers have shown the effect of microstructure on macroscopic properties of rock such as elasticity, bulk modulus, compressibility, and permeability. So, to deal with this issue, some studies have been published on the relationship between PVC and mineralogy of different consolidated and unconsolidated rock formations such as Newman (1973), Zimmerman (1991), Harari et al. (1995), and (Horne, 1997). Horne (1997) has proposed three nonlinear relationship between initial porosity and PVC for consolidated and unconsolidated sandstones and consolidated limestones.

However, except for simple cases of reservoir management, a universal relation between PVC and stress for different rock types should be required. Therefore, some studies have developed some stress related pore compressibility for reservoir rocks mainly based on experimental approaches. Harari et al. (1995) have worked on four limestone lithologies from Saudi Arabia basins under condition of hydrostatic differential stresses to study pore compressibility at constant pore pressure. They showed that a power law equation is adequately appropriate to evaluate differential stress related pore compressibility at constant pore pressure. Also, they found that sensitivity of pore compressibility at lower stress values is higher that from its at higher stress conditions. Based on their study, no distinct and universal relation was found, because the theoretical background to support the idea of the selection of regression formula was not declared. However, validity of their model is acceptable for qualitative and comparison studies on associated with rock samples from Saudi's basins. Oliveira et al. (2016) have shown a power law curve fit suitable on the PVC vs. confining pressure experimental data. But, in a different way, Liu et al. (2009) have derived two universal theoretical formulations for pore and bulk compressibilites of rocks using a novel conceptualization of the heterogeneous rock into two distinct parts, which one part follows a natural-strain-based Hooke's law, and the other part obeys an engineering-strain-based Hooke's law. Consequently, they proposed a universal exponential equation for the PVC-stress relationship as follows;

$$
C_{\mathrm{pc}}=C_{\mathrm{pc}}^{\infty}+\frac{\gamma}{\phi_{0} K} \exp \left(-\frac{\sigma}{K}\right)
$$

Where, $\mathrm{C}_{\mathrm{pc}}$ is the pore compressibility, is the pore compressibility, $\sigma$ is the hydrostatic confining stress, $\Phi_{0}$ is unstressed initial porosity, and $\mathrm{C}^{\infty}{ }_{\mathrm{pc}}, \mathrm{y}$, and $\mathrm{K}$ are constants which can be evaluated by fitting of the equation on experimental data points.

Based on the concept proposed by Liu et al. (2009), more studies were done by Wang et al. (2009), Moosavi et al. (2014), Zheng et al. (2016), Liu et al. (2016), and Rinaldi and Rutqvist (2019). They have studied other stress related petrophysical characteristics of rocks. These studies have examined the robustness of the mathematical exponential expression and its ability to prove porosity-stress and permeability-stress relations as well.

Accordingly, in the present study, because of its proved capability in the literature for fitting on the stress related PVC data points, the mathematical concept of eq. (1) was selected to interpret the experimental observations. In order to categorize and classify the pore volumetric changes of carbonate rocks under stress variation, about 200 core plug sample were collected from Asmari and Bangestan reservoir horizons in southern Iran. Porosity, permeability, grain density as well as detailed petrographically studies were done for all of the selected thin section samples. But, prior to sample selection for testing, a vast petrographical study was performed to classified the samples based on the geological aspect of carbonates which ones are dominant on microphysical? properties of the porous media. Therefore, petrographical studies were done on 3306 thin sections from Asmari formation which were collected from key wells in Maroon, Rag 
Sefid, Gachsaran, Bibi Hakimeh, and Aghajari oilfields and 396 thin sections from Bangestan reservoir horizon of Maroon and Rag-Sefid oilfields. But due to uncertainty in some samples, a number of thin-section samples were removed from the analysis process in the geological classification.

This paper is organized as follows. It first presents the investigation of the main effective petrographic characteristics of carbonate reservoir rocks which have significant effect on the behavior of the porous rocks under stress regimes. Moreover, an appropriate lithological-textural classification was proposed based on the frequencies of the important aspects. Then, in the second part of the study, experimental tests were performed on the 200 corresponding core plug samples. The experimental tests were including porosity, permeability as well as pore volume compressibility determination. The PVC-stress curves fitted on the prementioned mathematical equation to find out the corresponding fitting constants. Comparisons were then made between these experimentally driven constants as full description indices of volumetric changes due to stress change, and rock classification.

\section{Petrographic Studies And Rock Typing}

Different rock typing methods have been developed to categorize reservoir rocks into petrophysical units based on geological characteristics (Dou et al., 2011; El Sawy et al., 2020). Previous studies have shown the importance of lithology/mineralogy, texture, and porosity on the pore compressibility of reservoir carbonate rocks (Aloki Bakhtiari et al., 2011; Lis-Śledziona, 2019; Satter and Iqbal, 2016; Sui et al., 2020). The selection of rock typing method with the aim of sample selection for further experimental tests, needs to have an adequate understanding and distinguishing between different classification criteria. But according to previous studies, lithology, texture and amount and type of porosity are the most important parameters controlling the pore compressibility of carbonate rock. Therefore, the best method for classifying carbonate rocks would be one in which all lithological, textural, and porosity boundaries are considered. In order to identify the different classifications of voids in carbonate rocks, a brief explanation of some routine classification method is provided.

Archie (1952) was the first researcher who has linked rock fabric with petrophysical properties of carbonate rock in his classification. This skeleton classification with symbols is used to estimate petrophysical data, such as porosity, permeability, capillary pressure, and electrical conductivity. But since these descriptive features cannot be defined in terms of sedimentary or diagenetic terms, it is difficult to relate these features to geological models. Furthermore, a major problem is that no prediction has been made to distinguish visible interparticle spaces from other types of visible voids such as moldic porosity. However, the importance of the relationship between voids and sedimentary and diagenetic fabric and also distinguishing between interparticle spaces and other types of voids has been shown (Choquette and Pray, 1970; Lucia, 1983; Murray, 1960). Based on how the voids spaces are formed, Choquette and Pray (1970) divided all the carbonate voids into two major groups; fabric selective and non-fabric selective. According to this classification, moldic and intragranular voids are classified as fabric selective porosity and placed in a same group with interparticle and intercrystalline porosity. However, Lucia (1983) expressed that moldic and intragranular voids have different effects on petrophysical properties than interstitial and intercrystalline voids and should therefore be grouped separately. So, Lucia (1983) proposed a more general classification of carbonate porosity to be used in the carbonate rocks description. In his work, Lucia (1983) classified interparticle porosity based on the particle size and the dense or porous appearance of the interparticle area. Also, he classified vuggy porosity according to the type of interconnection. Separate vugs are defined as pore space that is interconnected only through interparticle pore space, whereas touching vugs are defined as ones that form an interconnected pore system independent of interparticle pore space. In this classification, separate vugs are typically fabric-selective in their origin. Intragranular and moldic pore spaces are examples of fabric-selective separate vugs. Touching vugs are typically nonfabric selective in origin. Cavernous, collapse breccia, fracture, and solution-enlarged fracture pore types commonly form an interconnected pore system on a reservoir scale and are typical touching-vug pore types.

In the present study, because of its comprehensiveness, the adequacy of Lucia (1983) carbonate classification were examined to use in the prediction of PVC for Asmari (Oligo-Miocene in age) and Bangestan group (Albian-Turonian in age) formations. These formations are the most important carbonate reservoir formations in the hydrocarbon fields of the Zagros Basin, Iran. So, 3702 thin sections from these formations (in 8 key wells) were selected. These samples were studied by polarizing microscope for selective geological parameters (Table 1) during petrographical studies.

Table 1. Parameters described in the petrographic studies.

\begin{tabular}{|c|c|c|c|c|c|c|c|c|c|c|c|c|}
\hline \multirow[t]{2}{*}{ Well } & \multirow[t]{2}{*}{ Depth } & \multirow[t]{2}{*}{ Lithology } & \multicolumn{4}{|c|}{ Mineralogy } & \multirow[t]{2}{*}{ Texture } & \multicolumn{2}{|c|}{ Anhydrite (\%) } & \multicolumn{3}{|c|}{ Visual Porosity (\%) } \\
\hline & & & Calcite & Dolomite & Anhydrite & Quartz & & Nodule & Cement/Replacement & Interparticle & Intercrystalline & $\Lambda$ \\
\hline
\end{tabular}

According to petrographic studies, from the lithological point of view, the Asmari formation was composed of dolostone and limestone, while the Bangestan group formation (Sarvak), due to very limited dolomitization, was composed only of limestone. Geological studies of the Asmari formation in the studied wells have shown that the reservoir quality of this formation is not very dependent on its sedimentological characteristics, especially texture and is mainly affected by various diagenetic processes that affect this formation with different intensities and as a result have changed lithology and reservoir properties (Fig 1).

Diagenetic events, especially dolomitization, anhydrite precipitation, dissolution and calcite cementation are the main factors controlling the reservoir properties of the Asmari Formation. This causes in Lucia's classification, samples with the same texture as grainstone but different porosity and permeability are in the same class (class 1). On the other hand, the placement of specimens with different textures such as mudstone, wackestone and mud-dominated packstone and possibly different porosity and permeability in a class (class 3 ) also causes that in the selection of samples based on Lucia classification, all parameters affecting compressibility do not considered. On the other hand, the classification of carbonate samples and then sample selection, in the first stages of this study, should not be entirely dependent on a petrographic parameter such as the texture or dolomite crystal size (as in the Lucia classification). Because core or thin-section samples may not be available in many reservoirs, relying grouping to petrographic parameters reduces the efficiency of that grouping. On the other hand, the type of porosity used in the Lucia classification is interparticle porosity, and other types of porosity such as vuggy and moldic types are not included in this diagram, although these pore spaces can also affect compressibility. So, pinning down the exact nature of the visual inspection of thin sections and choosing an appropriate classification based on the micro-observation could not lead us to similar trends in each corresponding class. 
Therefore, in order to choose a right classification model, there should exist other influential characteristic such that reflecting pore geometry and its complexity as well. So, because the exact choice of the effective quantitative parameters was not applicable by thin section study due to the aforementioned reasons, a grouping model sufficiently rich via another setting of the characteristics was needed. However, it was required a different class of models entirely to deal with fundamentally different logical parameters, it should be reflecting the pore characterization which was not from obtained by thin section-based parameters. Therefore, in this study, it was preferred to use the common reservoir classification (pore-perm cross plots) with special attention to sedimentary texture, dolomite crystal size and existing limitations of the device in measuring compressibility. The values of porosity and permeability are representing characteristics of pore geometry and complexity as well.

So, based on the core analysis results, porosity-permeability cross-plots of the studied samples in different lithologies, textures and dolomite crystal sizes were prepared (Fig 2). The relationship between geological features and reservoir properties in the studied samples, especially Asmari samples, was complex and this made the process of selecting samples for compressibility tests difficult. For this reason, the parameters of lithology, porosity, permeability and frequency of samples in each porosity-permeability cell were the basis for sample selection. The distribution of samples in porosity-permeability cross-plot is such that by considering a network of porosity and permeability with dimensions of $5 \%$ porosity and permeability of a logarithmic unit and considering the frequency, lithology, texture and crystal size in each cell, sampling was performed.

\section{Experimental Tests And Interpretation}

The pore volume compressibility tests were performed by the CMS-300 (Fig 3). The device has 12 core holder, such that in each series of tests, a maximum of 12 samples can be placed in the device. The pore fluid is helium gas and the hydrostatic pressure can be provided by the device up to 10,000 psi under ambient temperature conditions. CMS-300 is able to measure porosity in the range of 0.01 to $40 \%$, pore volume changes, gas permeability, Klinkenberg permeability (liquid equivalent permeability) and Forchheimer's coefficients at stepwise increasing overburden pressures from 800 to 10,000 psi. The length of the cores can be in a range between 0.75 inches to 4 inches. In this system, the pore volume is determined by Boyle's law. Boyle's law states that the volume of gas decreases with pressure, regularly. In other words, there is always an inverse relationship between volume and pressure at constant temperature. According to Boyle's law, at constant temperature the value of PV is equal to $n R T$. Where, in these relations, $\mathrm{P}$ is the gas pressure, $\mathrm{V}$ is the volume of gas, $\mathrm{n}$ is the number of moles of gas, $\mathrm{R}$ is the global constant of gases, and T represents the ambient temperature. Using the Boyle's law at constant temperature, the volume change can be calculated. Helium gas is injected at the same temperature from the tank chamber with a certain volume at a certain pressure to the sample holder. After gas expansion, the equilibrium pressure is recorded to measure the pore volume and the volume value is calculated using Boyle's law.

The recorded data form CMS-300 were processed to plot PVC vs. confining stress for different stress steps. Furthermore, using the equation (1) the trendline on the scattered processed data were matched automatically by a computer code. The coefficients of the trendline equation were summarized in the Table A1. Moreover, the interpretation of data for a sample is shown in Fig 4 and Table 2. For all of the samples the trendline based on equation (1) was very satisfactory such as depicted in Fig 4.

In order to evaluate the sensitivity of PVC to stress level it is appropriate to calculate percentage of the variation of PVC using the equation (1) as following;

$\% \Delta C_{\mathrm{pc}}=\frac{\Delta C_{\mathrm{pc}}}{C_{\mathrm{pc}}}=\frac{1}{C_{\mathrm{pc}}} \frac{d C_{p c}}{d \sigma} \Delta \sigma=-\frac{1}{K}\left(1-\frac{C_{\mathrm{pc}}^{\infty}}{C_{\mathrm{pc}}}\right) \Delta \sigma$

where $\% \Delta \mathrm{C}_{\mathrm{pc}}$ is percentage of the variation of PVC that defines the ratio of the PVC variation to the PVC. This variable is dependent to $\mathrm{C}_{\infty}$ and $\mathrm{K}$ coefficients as well as the value of PVC. As PVC decreases (or stress increases), the stress sensitivity of PVC decreases as well. As an example, for core sample No. 91 (Table 2) the percentage of the variation of PVC is $54 \%$ for stress change from 2000 psi to 3000 psi $(\Delta \sigma=1000$ psi). While in the case of stress change from $4000 \mathrm{psi}$ to $5000 \mathrm{psi}(\Delta \sigma=1000 \mathrm{psi})$, this value is equal to $29 \%$. Then, this sensitivity analysis has indicated the importance of having stress dependent PVC especially at each level of low stress regimes.

Table 2. Data interpretation for a sample (Sample No. 91).

\begin{tabular}{|c|c|c|c|c|c|c|c|}
\hline $\begin{array}{c}\sigma \\
(p s i)\end{array}$ & $\begin{array}{c}\phi \\
(\%)\end{array}$ & $\begin{array}{c}k \\
(m d)\end{array}$ & $\begin{array}{c}C_{p c} \\
\left(p s i^{-1}\right)\end{array}$ & $\begin{array}{c}C_{\mathrm{pc}}^{\infty} \\
\left(p s i^{-1}\right)\end{array}$ & $\begin{array}{l}\phi_{0} \\
(\%)\end{array}$ & $\begin{array}{c}\gamma \\
(\%)\end{array}$ & $\begin{array}{c}K \\
(p s i)\end{array}$ \\
\hline 800 & 17.1 & 0.327 & $2.71 \mathrm{E}-05$ & $3.11 \mathrm{E}-06$ & 17.5 & 0.899 & 1364.65 \\
\hline 1300 & 17.0 & 0.313 & $1.67 \mathrm{E}-05$ & & & & \\
\hline 2000 & 16.9 & 0.296 & $1.08 \mathrm{E}-05$ & & & & \\
\hline 3000 & 16.7 & 0.277 & $7.16 \mathrm{E}-06$ & & & & \\
\hline 4300 & 16.5 & 0.257 & $4.98 \mathrm{E}-06$ & & & & \\
\hline 6000 & 16.4 & 0.237 & $3.55 \mathrm{E}-06$ & & & & \\
\hline
\end{tabular}

\section{Results And Discussion}

To analyse the validity and accuracy of the empirical model based on the theory developed by Liu et al. (2009), the comparison of the experimentally obtained results were done with respect to the trendline curve from the equation (1). In all 200 core samples the trendline was very satisfactory with the value of the coefficient of determination $\left(R^{2}\right)$ greater than 0.97 which reflects the high validity and accuracy of the mathematical model. While various researchers proposed power law equations instead, the comparison between the exponential equation (1) and the power law regression was done. The present study has

Page $4 / 11$ 
shown that the exponential equation (1) is more accurate than the power law formula. Moreover, the power law regression model has not theoretical background. Also, the lack of interpretability is another problem related to this equation for the PVC-stress curve fitting. At the lower stress levels the difference between the experimental results and the power law regression is dramatically increased because of the existence of a vertical asymptotic of the curve while confining stress approaches to zero, mathematically. However, such a situation does not occur in the case of using the exponential equation.

The values of the coefficients associated with the theoretical trendline between PVC and stress for different frequent porosity-permeability classes were shown in Table 3 for the limestones and in Table 4 for dolostones. For each of the coefficients, average value as well as the lower and upper bounds were presented. This bandwidth provides a significant tool in order to determine the limits of parametric effects in the reservoir models. The upper and lower bounds were obtained from the upper and lower PVC-stress curves in each category, while the average values were obtained from the arithmetic mean of the corresponding values. Fig 5 represents the plots of values in the Table 3 for the limestones and Fig 6 shows this plots for dolostones as listed in Table 4 .

Furthermore, to turn the attention to the validity of the proposed model for prediction where the experimental PVC-stress data is not available, 12 arbitrary samples were collected with porosity-permeability in the range of the frequent categories and also 3 out-of-range data. The experimental data from the PVC test have shown the acceptancy of the proposed estimation curves both for in-range and out-of-range core samples. The results have shown in the Fig 7 for the 12 in-range. Adjacent cells in cross-plot were used to estimate the coefficients of PVC-stress curve for data whose porosity-permeability was outside the frequency ranges. Fig 8 presents the prediction curves as well as experimentally data for these three core samples. The results have indicated that at least over most of the range of experimentally or in-situ accessible porosity and permeability data, the proposed estimations are applicable.

Int the application of reservoir modelling it is useful to determine the representative elementary volume (REV) for the model, and based on the corresponding porosity and permeability profile in REV, the average values of porosity and permeability can be utilized to implement the correlated PVC-stress curve for each of REVs.

Table 3. The values of coefficients $\mathrm{C}_{\infty} \mathrm{Y}$ and $\mathrm{K}$ for limestone samples based on the classification of porosity-permeability frequent groups.

\begin{tabular}{ccccccccccc}
\hline \multirow{2}{*}{$\phi_{0}$} & \multirow{2}{*}{$k_{0}$} & \multicolumn{3}{c}{ Lower bound } & \multicolumn{3}{c}{ Upper bound } & \multicolumn{3}{c}{ Average } \\
\cline { 2 - 12 } & $C_{\mathrm{pc}}^{\infty}$ & $\gamma$ & $K$ & $C_{\mathrm{pc}}^{\infty}$ & $\gamma$ & $K$ & $C_{\mathrm{pc}}^{\infty}$ & $\gamma$ & $K$ \\
\hline $0-10$ & $0.01-0.1$ & 3.80 & 0.49 & 1286.67 & 9.07 & 0.79 & 1358.98 & 5.60 & 0.56 & 1333.19 \\
$0-5$ & $0.1-1$ & 3.20 & 0.28 & 1056.50 & 33.4 & 1.18 & 1799.10 & 11.97 & 0.73 & 1348.65 \\
$0-5$ & $1-10$ & 7.32 & 0.66 & 1168.92 & 10.53 & 0.96 & 1310.8 & 8.88 & 0.84 & 1253.89 \\
$5-10$ & $0.1-1$ & 3.04 & 0.38 & 1346.30 & 6.67 & 0.86 & 1360.84 & 5.16 & 0.65 & 1351.02 \\
$5-10$ & $1-10$ & 3.81 & 0.54 & 1307.98 & 10.5 & 1.01 & 1359.31 & 6.32 & 0.79 & 1353.87 \\
$10-15$ & $0.1-1$ & 2.15 & 0.48 & 1359.30 & 4.07 & 0.86 & 1366.36 & 3.14 & 0.64 & 1362.97 \\
$10-15$ & $1-10$ & 2.63 & 0.57 & 1357.07 & 5.21 & 1.12 & 1364.88 & 3.53 & 0.76 & 1362.09 \\
$15-20$ & $0.1-1$ & 1.57 & 0.51 & 1362.3 & 3.85 & 1.01 & 1368.13 & 2.59 & 0.74 & 1365.65 \\
$15-20$ & $1-10$ & 2.12 & 0.62 & 1356.88 & 5.87 & 1.53 & 1366.71 & 3.12 & 0.88 & 1364.49 \\
$15-20$ & $10-100$ & 2.58 & 0.76 & 1364.65 & 3.33 & 1.10 & 1366.09 & 2.99 & 0.92 & 1365.16 \\
\hline
\end{tabular}

* Units: $C_{\mathrm{pc}}^{\infty}\left[\times 10^{-6} \mathrm{psi}^{-1}\right], \gamma$ and $\phi_{0}[\%], k_{0}[\mathrm{mD}]$, and $K[\mathrm{psi}]$.

Table 4. The values of coefficients $\mathrm{C}_{\infty} \mathrm{pc}, \mathrm{Y}$ and $\mathrm{K}$ for dolostone samples based on the classification of porosity-permeability frequent groups.

\begin{tabular}{ccccccccccc}
\hline \multirow{2}{*}{$\phi_{0}$} & \multirow{2}{*}{$k_{0}$} & \multicolumn{3}{c}{ Lower bound } & \multicolumn{3}{c}{ Upper bound } & \multicolumn{3}{c}{ Average } \\
\cline { 2 - 12 } & & $C_{\mathrm{pc}}^{\infty}$ & $\gamma$ & $K$ & $C_{\mathrm{pc}}^{\infty}$ & $\gamma$ & $K$ & $C_{\mathrm{pc}}^{\infty}$ & $\gamma$ & $K$ \\
\hline $0-10$ & $0.01-0.1$ & & & & & & & 6.39 & 0.77 & 1345.54 \\
$0-5$ & $0.1-1$ & & & & & & & 56.3 & 0.65 & 1214.95 \\
$5-10$ & $0.1-1$ & 3.45 & 0.51 & 1327.64 & 11.3 & 1.22 & 1359.55 & 6.65 & 0.88 & 1346.19 \\
$5-10$ & $1-10$ & 4.03 & 0.60 & 1345.57 & 6.91 & 1.00 & 1360.42 & 5.23 & 0.75 & 1353.45 \\
$10-15$ & $0.1-1$ & 1.95 & 0.46 & 1351.21 & 6.96 & 1.55 & 1366.99 & 4.16 & 0.85 & 1359.88 \\
$10-15$ & $1-10$ & 2.29 & 0.49 & 1353.21 & 5.71 & 1.21 & 1366.68 & 3.55 & 0.78 & 1362.23 \\
$10-15$ & $10-100$ & 2.52 & 0.59 & 1356.25 & 5.07 & 1.11 & 1365.26 & 3.98 & 0.85 & 1360.39 \\
$15-20$ & $1-10$ & 1.69 & 0.46 & 1363.36 & 3.52 & 1.04 & 1367.85 & 2.81 & 0.78 & 1365.26 \\
$15-20$ & $10-100$ & 2.50 & 0.78 & 1362.90 & 3.86 & 1.16 & 1366.16 & 3.01 & 0.88 & 1364.95 \\
$20-25$ & $10-100$ & 1.45 & 0.54 & 1362.14 & 4.21 & 1.43 & 1368.83 & 2.82 & 1.01 & 1365.68 \\
\hline
\end{tabular}

* Units: $C_{\mathrm{pc}}^{\infty}\left[\times 10^{-6} \mathrm{psi}^{-1}\right], \gamma$ and $\phi_{0}[\%], k_{0}[\mathrm{mD}]$, and $K[\mathrm{psi}]$.

\section{Summary And Conclusion}

The PVC literature abounds with tributes to the empirical PVC-porosity relation. But only in the last few years special attention have been paid to the importance of having PVC-stress relation. Therefore, due to the importance of the effect of stress on PVC, and also the importance of having corrlation to estimate the relationship in the case of no experimental PVC-stress data, in this paper we have combined petrographical and laboratory studies to achieve the goal. First, we have discussed the complexity of common geological categorizations based on pore structural inspection of thin sections for this estimate. So, we have used the petrophysical properties of rock including porosity and permeability and also lithological description of samples to find out the empiricaltheoretical-based correlation between PVC and stress for different cases. Accordingly, lots of thin section and previously gathered core data were studied for two important reservoir formations of Iran; Bangestan and Asmari. As the effect of geological pore structure complexity exhibits in the porosity and permeability of core samples, the most frequent porosity-permeability was chosen as a base for sample selection in order to perform PVC experimental tests. Then 200 core samples were tested and analyzed. Based on the pre-approved theoretical equation, the PVC-stress relations were quantified and then this 
categorization for estimating the relation coefficients was well examined on 15 different core samples that was not involved in the process of determination of the coefficients.

Furthermore, the present experimental study has even proved the validity of the theoretical exponential relationship between PVC and stress which has been proposed by Liu et al. (2009). We have shown that the equation is useful for understanding the effect of reservoir production on volumetric change of pores. It has shown that the sensitivity of PVC to stress is not ignorable, such that reported in the literature. So, dismissing the stress effect on PVC as a material property information of porous rock contained in reservoir modeling, lead to error in accurate analysis. The sensitivity analysis of the equation revealed that with stress changes, significant changes occur in the value of PVC, especially at low stress levels.

\section{References}

Aloki Bakhtiari, H., Moosavi, A., Kazemzadeh, E., Goshtasbi, K., Esfahani, M. R., and Vali, J., 2011, The effect of rock types on pore volume compressibility of limestone and dolomite samples: Geopersia, v. 1, no. 1, p. 37-82.

Archie, G. E., 1952, Classification of Carbonate Reservoir Rocks and Petrophysical Considerations*: AAPG Bulletin, v. 36, no. 2, p. $278-298$.

Choquette, P. W., and Pray, L. C., 1970, Geologic Nomenclature and Classification of Porosity in Sedimentary Carbonates: AAPG Bulletin, v. 54, no. 2, p. 207250.

Chuanliang, L., Xiaofan, C., and Zhimin, D., 2004, A New Relationship of Rock Compressibility with Porosity: SPE Asia Pacific Oil and Gas Conference and Exhibition, APOGCE.

da Silva, G. P., Franco, D. R., Stael, G. C., da Costa de Oliveira Lima, M., Sant'Anna Martins, R., de Moraes França, O., and Azeredo, R. B. V., 2015, Petrophysical studies of north American carbonate rock samples and evaluation of pore-volume compressibility models: Journal of Applied Geophysics, v. 123 , p. 256-266.

Dou, Q., Sun, Y., and Sullivan, C., 2011, Rock-physics-based carbonate pore type characterization and reservoir permeability heterogeneity evaluation, Upper San Andres reservoir, Permian Basin, west Texas: Journal of Applied Geophysics, v. 74, no. 1, p. 8-18.

El Sawy, M. Z., Abuhagaza, A. A., Nabawy, B. S., and Lashin, A., 2020, Rock typing and hydraulic flow units as a successful tool for reservoir characterization of Bentiu-Abu Gabra sequence, Muglad basin, southwest Sudan: Journal of African Earth Sciences, v. 171, p. 103961.

Geertsma, J., 1957, The Effect of Fluid Pressure Decline on Volumetric Changes of Porous Rocks: Transactions of the AIME, v. 210, no. 01, p. $331-340$.

Hall, H. N., 1953, Compressibility of Reservoir Rocks: Journal of Petroleum Technology, v. 5, no. 01, p. 17-19.

Harari, Z., Shu-Teh, W., and Salih, S., 1995, Pore-Compressibility Study of Arabian Carbonate Reservoir Rocks: SPE Formation Evaluation, v. 10, no. 04, p. 207214.

Horne, R. N., 1997, Modern Well Test Analysis: A Computer-aided Approach, Petroway.

Jalalh, A. A., 2006a, Compressibility of porous rocks: Part I. Measurements of Hungarian reservoir rock samples: Acta Geophysica, v. 54, no. 3, p. $319-332$.

-, 2006b, Compressibility of porous rocks: Part II. New relationships: Acta Geophysica, v. 54, no. 4, p. 399-412.

Lis-Śledziona, A., 2019, Petrophysical rock typing and permeability prediction in tight sandstone reservoir: Acta Geophysica, v. 67, no. 6, p. $1895-1911$.

Liu, H.-H., Lai, B., Chen, J., and Georgi, D., 2016, Pressure Pulse-Decay Tests in a Dual-Continuum Medium: Late-Time Behavior: Journal of Petroleum Science and Engineering, v. 147.

Liu, H.-H., Rutqvist, J., and Berryman, J., 2009, On the relationship between stress and elastic strain for fractured rock: International Journal of Rock Mechanics and Mining Sciences, v. 46, p. 289-296.

Lucia, F. J., 1983, Petrophysical Parameters Estimated From Visual Descriptions of Carbonate Rocks: A Field Classification of Carbonate Pore Space: Journal of Petroleum Technology, v. 35, no. 03, p. 629-637.

Moosavi, S. A., Goshtasbi, K., Kazemzadeh, E., Bakhtiari, H. A., Esfahani, M. R., and Vali, J., 2014, Relationship between porosity and permeability with stress using pore volume compressibility characteristic of reservoir rocks: Arabian Journal of Geosciences, v. 7, no. 1, p. $231-239$.

Murray, R. C., 1960, Origin of porosity in carbonate rocks: Journal of Sedimentary Research, v. 30, no. 1, p. 59-84.

Newman, G. H., 1973, Pore-Volume Compressibility of Consolidated, Friable, and Unconsolidated Reservoir Rocks Under Hydrostatic Loading: Journal of Petroleum Technology, v. 25, no. 02, p. 129-134.

Oliveira, G. L. P. d., Ceia, M. A. R., Missagia, R. M., Archilha, N. L., Figueiredo, L., Santos, V. H., and Lima Neto, I., 2016, Pore volume compressibilities of sandstones and carbonates from Helium porosimetry measurements: Journal of Petroleum Science and Engineering, v. 137, p. $185-201$.

Rinaldi, A. P., and Rutqvist, J., 2019, Joint opening or hydroshearing? Analyzing a fracture zone stimulation at Fenton Hill: Geothermics, v. 77, p. 83-98. 
Satter, A., and Iqbal, G. M., 2016, 3 - Reservoir rock properties, in Satter, A., and Iqbal, G. M., eds., Reservoir Engineering: Boston, Gulf Professional Publishing, p. 29-79.

Sui, W., Quan, Z., Hou, Y., and Cheng, H., 2020, Estimating pore volume compressibility by spheroidal pore modeling of digital rocks: Petroleum Exploration and Development, v. 47, no. 3, p. 603-612.

Teeuw, D., 1971, Prediction of Formation Compaction from Laboratory Compressibility Data: Society of Petroleum Engineers Journal, v. 11, no. 03, p. 263-271. van der Knaap, W., 1959, Nonlinear Behavior of Elastic Porous Media: Transactions of the AIME, v. 216, no. 01, p. $179-187$.

Wang, X.-S., Jiang, X.-W., Wan, L., Song, G., and Xia, Q., 2009, Evaluation of depth-dependent porosity and bulk modulus of a shear using permeability-depth trends: International Journal of Rock Mechanics and Mining Sciences, v. 46, no. 7, p. 1175-1181.

Zheng, J., Ju, Y., Liu, H.-H., Zheng, L., and Wang, M., 2016, Numerical prediction of the decline of the shale gas production rate with considering the geomechanical effects based on the two-part Hooke's model: Fuel, v. 185, p. 362-369.

Zimmerman, R. W., 1991, Compressibility of Sandstones, Amsterdam, Elsevier.

\section{Figures}
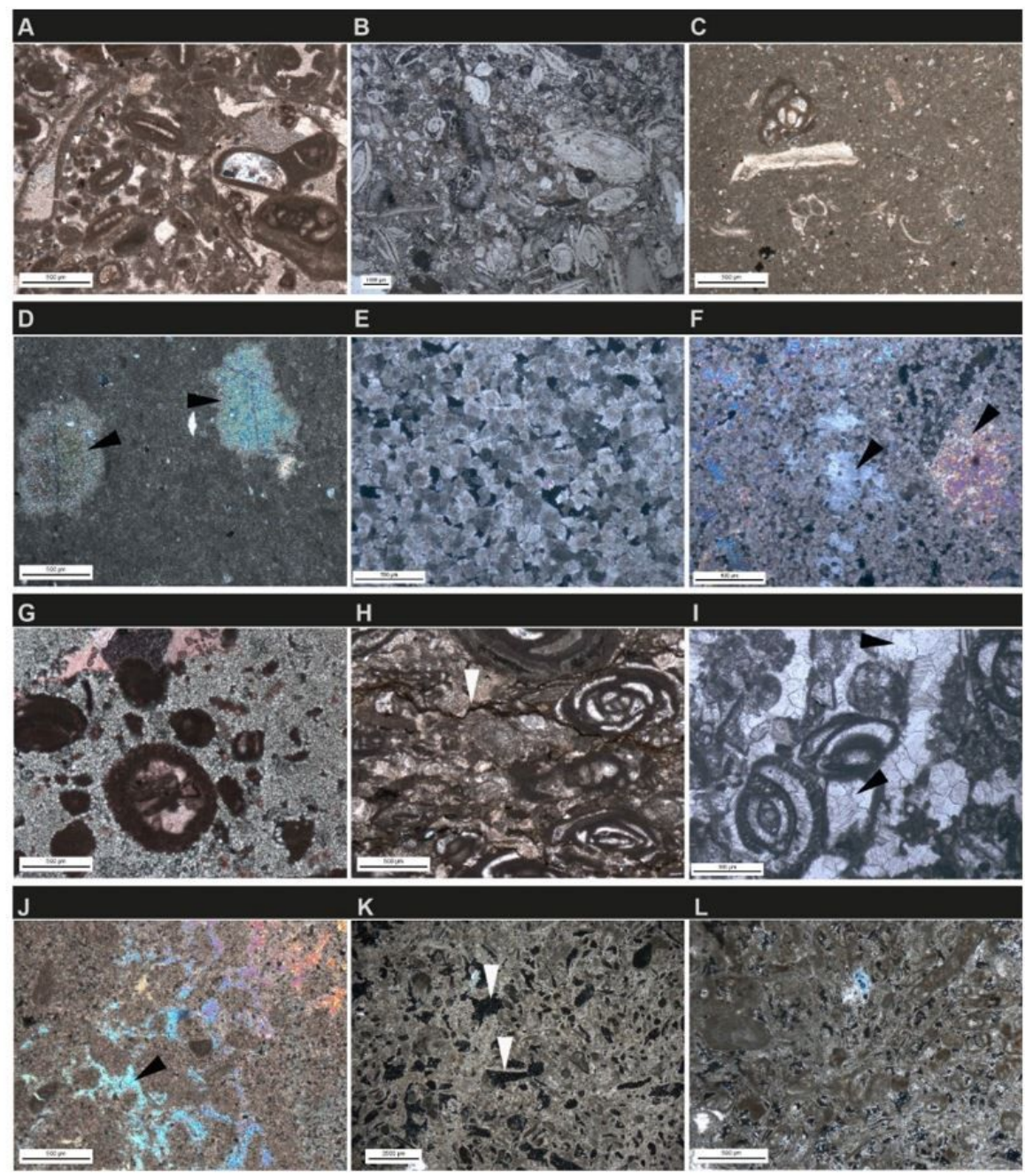

\section{Figure 1}

Photomicrographs of the Asmari formation in the studied fields. A-D showing different textures (A: grainstone; B: packstone; C: wackestone; D: mudstone with anhydrite nodules-arrows); E-G: showing dolostone samples with different crystal size (E: coarse crystalline; F: medium crystalline with anhydrite precipitationarrows; G: fine crystalline); H: stylolite as a chemical compaction feature; l: calcite cementation; J: anhydrite precipitation in a fine crystalline dolopackstone: K: dissolution porosities; L: interparticle pore spaces in a skeletal grainstone. 


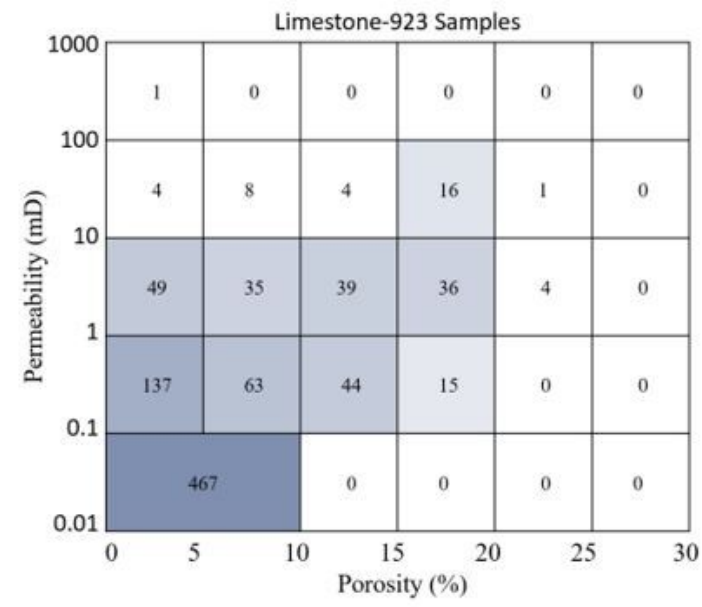

(a)

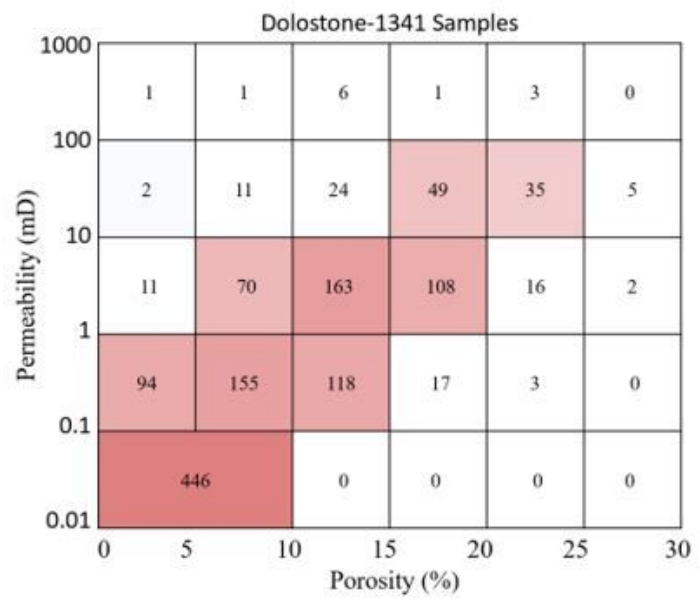

(b)

\section{Figure 2}

Porosity-permeability cross plots with the most frequent data samples for (a) Limestone, (b) Dolostone.

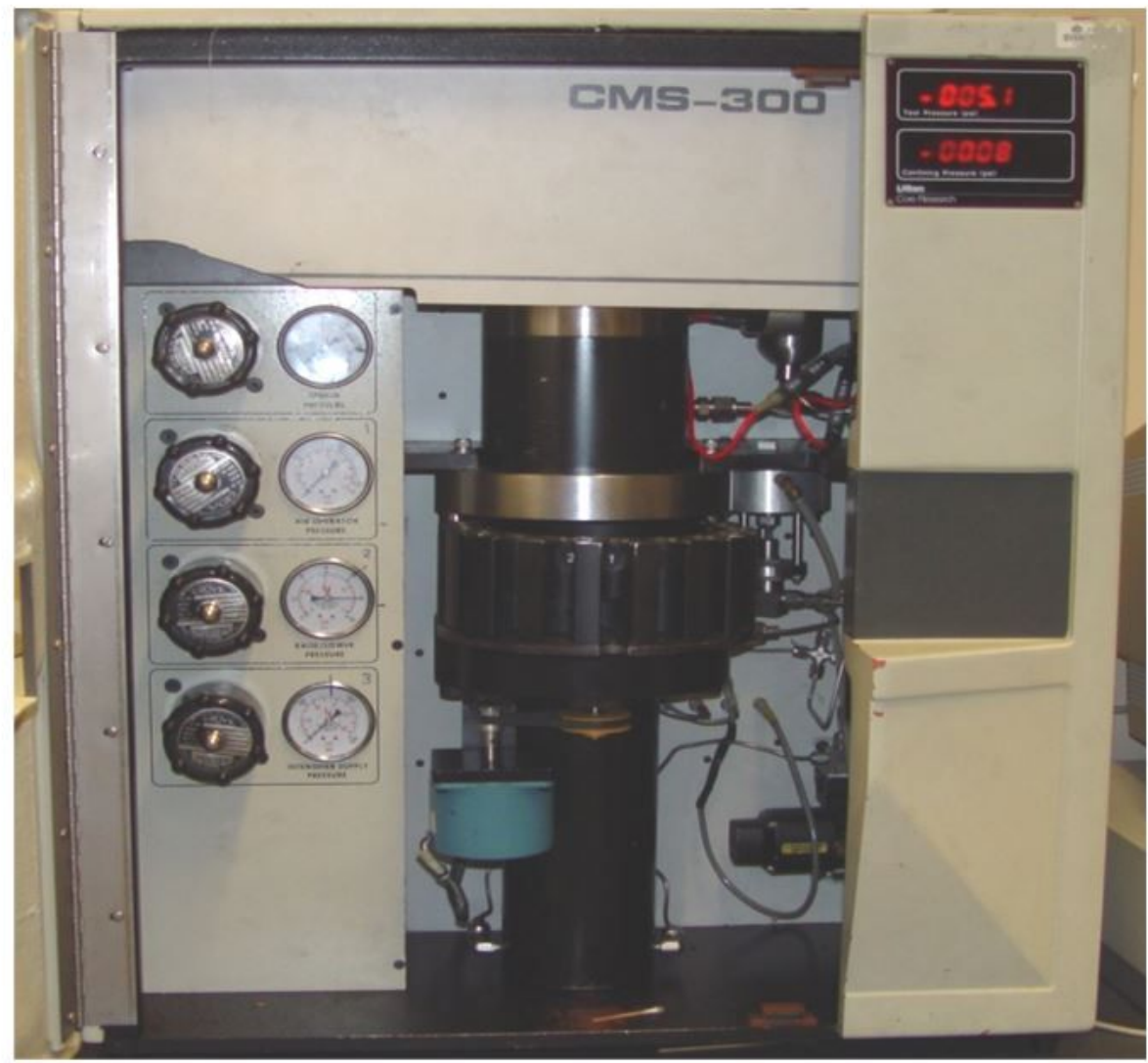

Figure 3

The CMS-300 machine. 


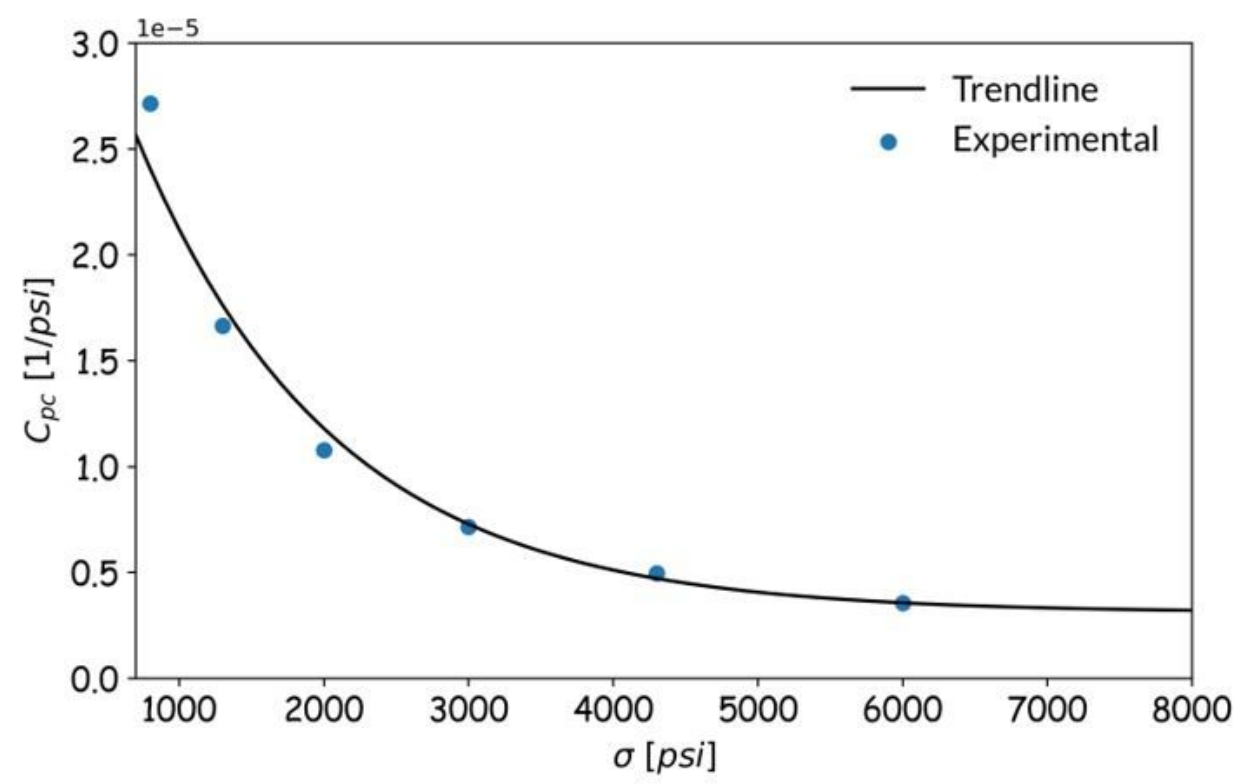

Figure 4

PVC (C_pc) vs. confining stress ( $\sigma$ ) for a sample (Sample No. 91).
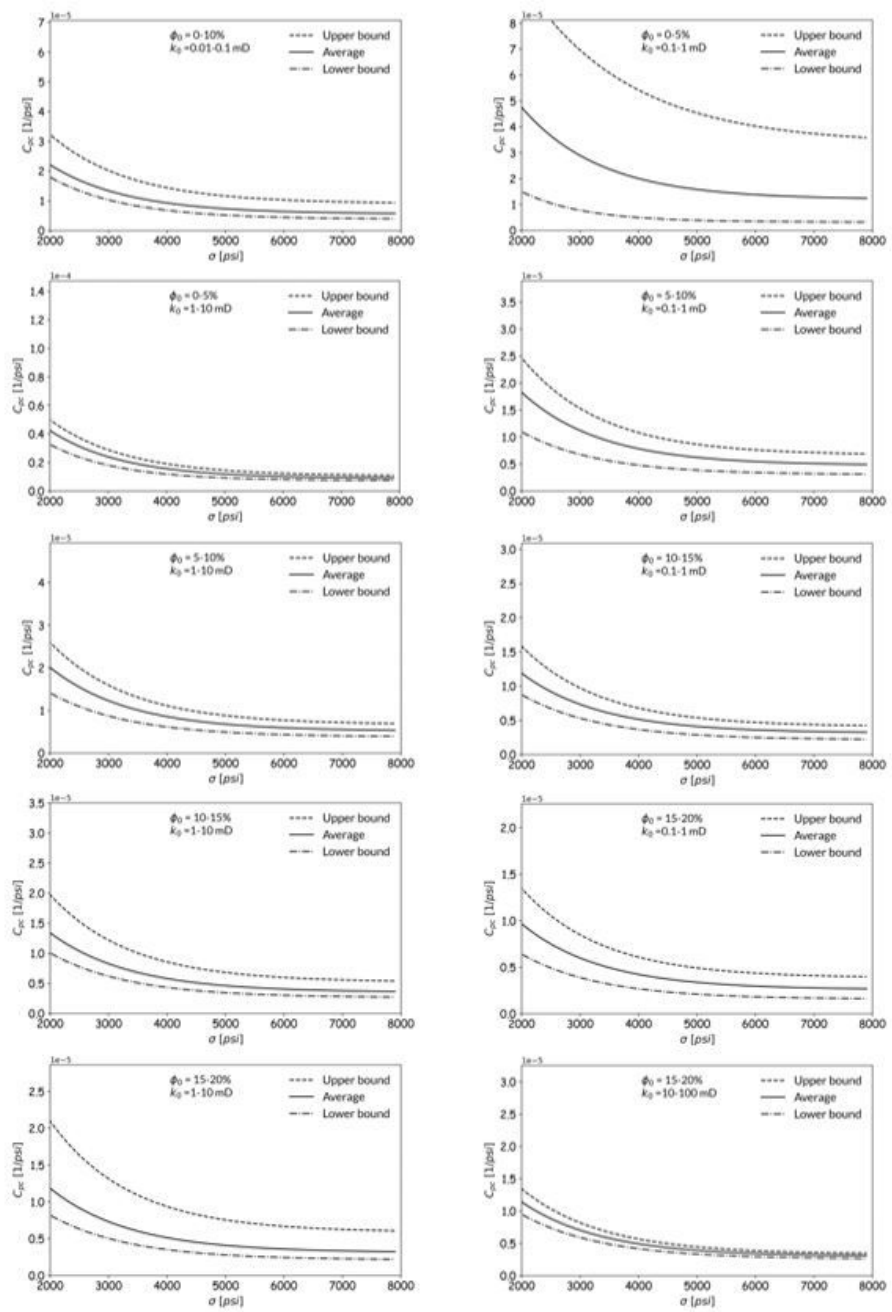

\section{Figure 5}

The PVC-stress curves for limestone samples based on the classification of porosity-permeability frequent groups. 

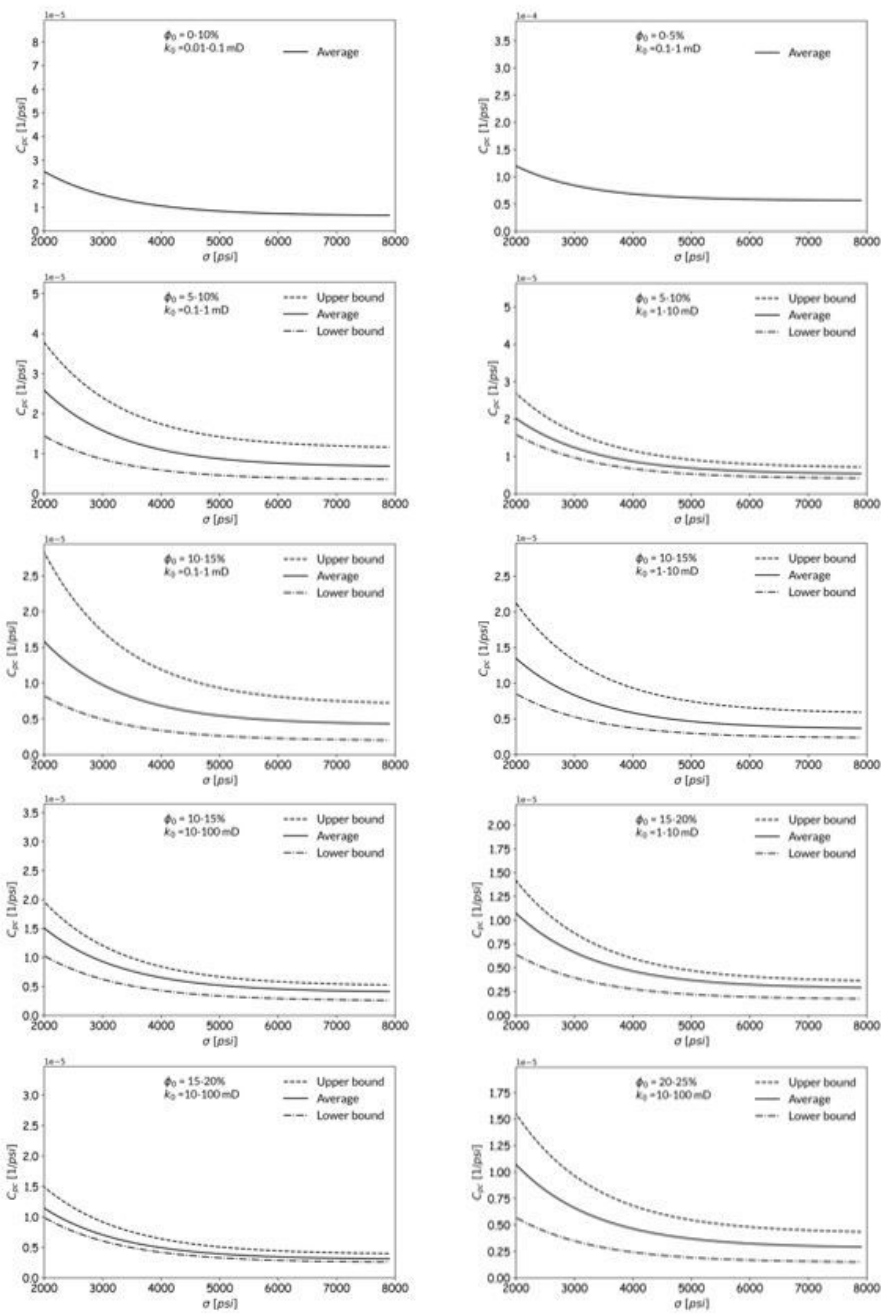

\section{Figure 6}

The PVC-stress curves for dolostone samples based on the classification of porosity-permeability frequent groups. 

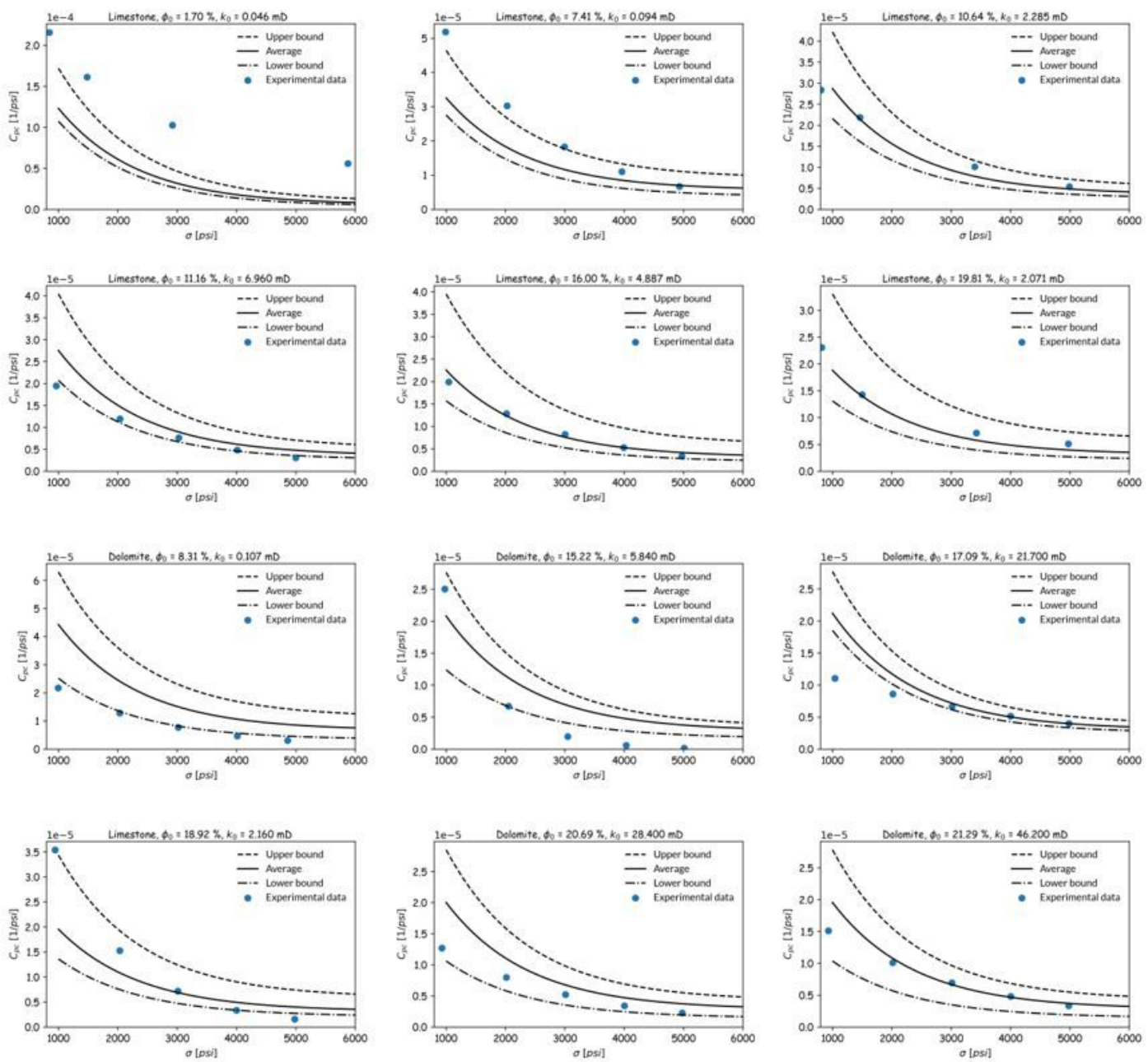

\section{Figure 7}

Verification of the proposed correlation for limestone and dolostone samples based on the classification of porosity-permeability frequent groups for samples that their porosity-permeability are in the range of the frequent groups.
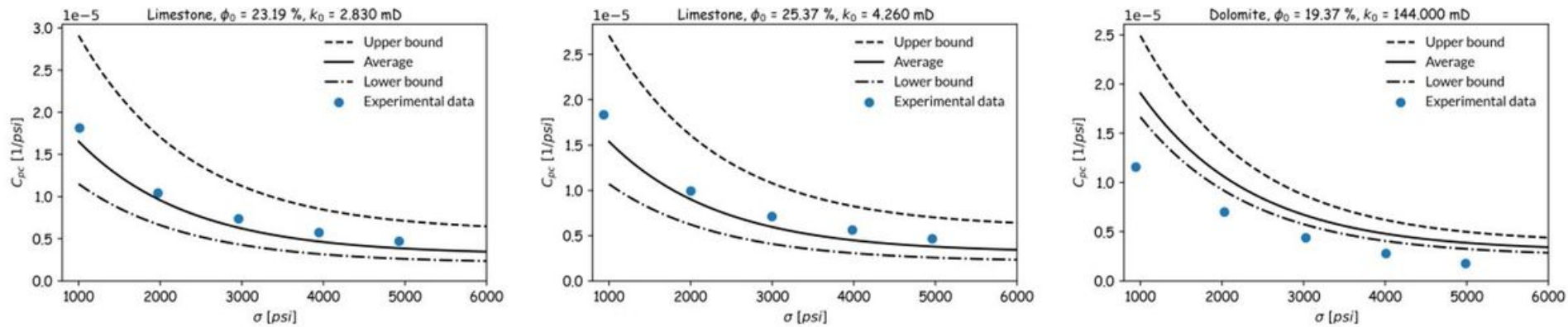

\section{Figure 8}

Verification of the proposed correlation for limestone and dolostone samples based on the classification of porosity-permeability frequent groups for samples that their porosity-permeability are not in the range of the frequent groups.

\section{Supplementary Files}

This is a list of supplementary files associated with this preprint. Click to download.

- Appendix.docx 